\title{
Outcomes of transposition of the great arteries in the era of atrial inflow correction
} D Birnie, A Tometzki, J Curzio, A Houston, S Hood, L Swan, W Doig, N Wilson,
M Jamieson, J Pollock, W S Hillis

\begin{abstract}
Objective-To examine long term morbidity and mortality following atrial inflow corrective procedures for transposition of the great arteries (TGA) and to investigate factors that influence morbidity and mortality.

Design-Retrospective cohort study from a single centre.

Setting-Cardiology and cardiothoracic surgical unit in a large tertiary referral centre.

Patients-All 130 patients who had TGA diagnosed between August 1972 and May 1988 and were considered suitable for atrial inflow correction; 109 of these underwent surgery (operative cohort: 84 Mustard operations and 25 Senning operations); 95 survived to hospital discharge (hospital surviving cohort).

Main outcome measures-Death and cardiac events.

Results-There were relatively good long term results from atrial inflow correction for TGA with 5, 10, and 15 year survivals of $77.3 \%, 75.9 \%$, and $71.3 \%$. However, there was an appreciable incidence of late cardiac death and events, with 5, 10, and 15 year cardiac event-free survivals of $74.5 \%, 67.1 \%$, and $39.6 \%$. Supraventricular tachycardia was the only significant risk factor for late cardiac death (relative risk $8.72,95 \%$ confidence interval, 2.86 to 26.64). Senning patients had better eventfree survival $(p=0.04)$.

Conclusions-Atrial inflow correction for TGA has a reasonably good 15 year survival $(71.3 \%)$, but there is an appreciable incidence of late cardiac deaths and events (15 year event-free survival $39.6 \%$ ). The Senning procedure is preferable to the Mustard procedure for cases unsuitable for arterial switching.

(Heart 1998;80:170-173)
\end{abstract}

Keywords: transposition of the great arteries; congenital heart disease; Mustard operation; Senning operation

Untreated, $90 \%$ of infants with complete transposition of the great arteries (TGA) will die during the first year. ${ }^{1}$ The introduction in the early 1960 s of atrial septostomy or septectomy followed by Senning, ${ }^{2}$ or Mustard, ${ }^{3}$ atrial inflow atrial corrective procedures transformed the prognosis of TGA. In the Senning procedure the atrial septum is relocated to direct, or "baffle", the venous inflow. In the
Mustard operation the atrial septum is excised and a pericardial or synthetic patch is used to direct the venous return. The right ventricle remains the systemic ventricle after either procedure. There has been a high reported incidence of late complications (including sudden death, systemic ventricular failure, and sick sinus syndrome), ${ }^{4-12}$ and thus since the mid1980s this approach has been largely superseded by definitive anatomical correction (arterial switching) in the neonatal period. ${ }^{13}$

The late complications make long term management of patients with palliative inflow correction increasingly difficult and thus we report the progress of a large cohort from a single centre. Previous reports have concentrated mainly on mortality whereas we also report non-fatal cardiac events.

\section{Methods}

We performed a retrospective analysis of the case notes of all 130 patients from the Royal Hospital for Sick Children (RHSC), Yorkhill, Glasgow catchment area who had TGA diagnosed between August 1972 and May 1988 and were considered suitable for atrial inflow correction. During this period inflow correction was the procedure of choice in Glasgow for this condition, and 109 of the 130 patients underwent these operations (operative cohort). There were 84 Mustard operations and 25 Senning operations. Choice of operation reflected the surgeon's preference rather than any particular patient characteristic. All of the children were diagnosed and followed up at RHSC, Glasgow, and 98 had their operations performed there. The other 11 had their operations in Leeds (10) and Edinburgh (1) during the years 1978 to 1980 . Lesions were classified as complex if there was associated ventricular septal defect requiring closure, or aortic coarctation or left ventricular outflow tract obstruction requiring intervention.

\section{FOLLOW UP}

The original operation notes and case notes were reviewed, including biannual ECGs and Holter monitoring. The patients were seen at least biannually at Yorkhill. Of the 95 patients in the operative cohort who survived to discharge from hospital, eight $(8.4 \%)$ moved out of the catchment area. Contact was made to obtain the clinical data from the centres moved to. Data collection was completed on 30 June 1995. Four of the group who did not have atrial inflow correction were lost to follow up and two of the correction group were lost. Hence the overall follow up was $95.3 \%$ with a
Accepted for publication 20 February 1998 
Table 1 Causes of late deaths

\begin{tabular}{llccl}
\hline Operation & Type & $\begin{array}{l}\text { Time since } \\
\text { operation (years) }\end{array}$ & $\begin{array}{l}\text { Age at death } \\
\text { (years) }\end{array}$ & Cause of death \\
\hline Mustard & Simple & 1.3 & 1.95 & Sudden death \\
Mustard & Simple & 11.2 & 11.75 & Sudden death \\
Mustard & Complex & 7.2 & 8.42 & Sudden death \\
Mustard & Simple & 15.1 & 16.85 & SVT \\
Mustard & Simple & 1.4 & 2.52 & SVT \\
Mustard & Simple & 3.5 & 4.16 & SVT \\
Senning & Complex & 6.4 & 7.04 & SVT \\
Mustard & Simple & 3.2 & 4.22 & Cerebral embolus \\
Mustard & Simple & 1.0 & 2.27 & Cerebral embolus \\
Mustard & Simple & 0.2 & 1.02 & Died after reop for baffle obstruction \\
Mustard & Simple & 0.3 & 0.52 & Died after reop for baffle obstruction \\
Mustard & Simple & 15.0 & 15.84 & Respiratory failure \\
Mustard & Simple & 12.7 & 13.57 & RV failure \\
Mustard & Simple & 1.5 & 1.92 & Severe cerebral damage after cardiac \\
& & & & arrest \\
\hline
\end{tabular}

Reop, reoperation; RV, right ventricular; SVT, supraventricular tachycardia.

$98 \%$ follow up of the operative cohort. The mean and median length of follow up of the operative cohort was 118.6 months and 124.8 months, respectively, with a range of 2.56 to 188.75 months.

STATISTICAL ANALYSIS

Survival analysis was performed using the Kaplan-Meier method. Comparison of survival curves was performed using the log-rank statistic. Cox regression analysis entering occurrence of atrial arrhythmias and loss of sinus rhythm as time dependent covariates was used to examine risks for late death.

\section{Results}

MORTALITY

One hundred and thirty patients with a diagnosis of TGA were considered anatomically suitable for atrial inflow correction. The number of new cases per year remained similar over the course of the study, averaging 8.5 a year (range 3 to 13). Of the 21 who did not have atrial inflow correction, four were lost to follow up and 17 died. The main causes of death were other cardiac operations (4) and cerebral haemorrhage/thrombosis/meningitis (4). All 109 patients in the operative cohort had septostomies. Fourteen deaths occurred within 30 days of atrial inflow correction and 95 patients survived to hospital discharge. There were 14 late deaths, and 13 of these were from cardiac causes. These are listed in table 1 .

INFLUENCE OF PREOPERATIVE AND OPERATIVE VARIABLES ON SURVIVAL

The Kaplan-Meier survival curves for the entire cohort are shown in fig 1 ; the 5, 10, and 15 year survival for the cohort was $77.3 \%$,

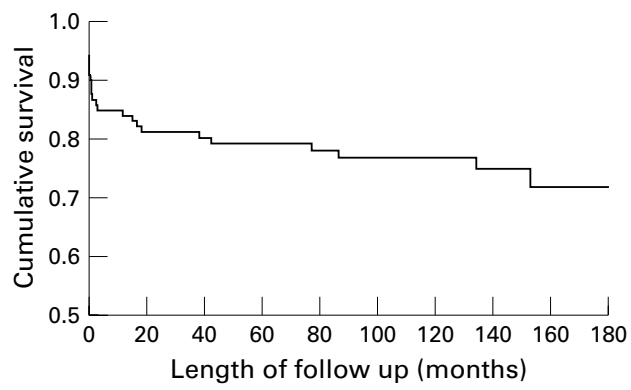

Figure 1 Kaplan-Meier survival curve of operative cohort $(n=109)$.
Table 2 Comparison of survival experience of the entire cohort $(n=109)$ using the log-rank statistic

\begin{tabular}{lll}
\hline Variable & $\begin{array}{l}\text { Log-rank } \\
\text { statistic }\end{array}$ & Significance \\
\hline Operation type & 0.59 & 0.42 \\
Simple or complex & 1.57 & 0.21 \\
Sex & 3.80 & 0.052 \\
Age at operation & 7.10 & 0.008 \\
$\begin{array}{l}\text { Surgical era (1974-81 v 1981-88) } \\
\text { Baffle material (endogenous } v\end{array}$ & 9.97 & 0.002 \\
$\quad \begin{array}{l}\quad \text { synthetic) } \\
\text { Cross clamp time (above } v \text { below } \\
\quad \text { median) }\end{array}$ & 0.05 & 0.082 \\
$\begin{array}{l}\text { Bypass time (above } v \text { below median) } \\
\quad\end{array}$ & 1.53 & 0.75 \\
\hline
\end{tabular}

Table 3 Causes of initial cardiac events after atrial inflow correction

\begin{tabular}{lc}
\hline Initial cardiac event & Number \\
\hline Death & 8 \\
Reoperation & 14 \\
$\quad$ Baffle problems & 1 \\
$\quad$ Other coarctation of aorta & 2 \\
$\quad$ Relief of LV outflow obstruction & 3 \\
Significant arrhythmia & 3 \\
$\quad$ Cardiac syncope & 2 \\
$\quad$ Supraventricular tachycardia & 9 \\
$\quad$ Permanent pacemaker & 2 \\
Right ventricular decompensation & \\
\hline
\end{tabular}

$75.9 \%$, and $71.3 \%$, respectively. Eight preoperative and operative variables were examined to assess their influence on survival (table 2). There were 95 hospital survivors and the 5, 10, and 15 year survival was $91.5 \%, 89.0 \%$, and $83.8 \%$, respectively. A survival analysis was performed on the group of hospital survivors and none of the factors influenced survival; hence the greater age at operation and the more recent surgical era had their beneficial influence within the immediate operative period and had no long term influence on survival.

\section{CARDIAC EVENTS}

Forty four (46\%) of the hospital survivors had experienced cardiac events. For the purpose of the analysis, only the first event experienced by an individual was included (table 3 ). The 5, 10, and 15 year event-free survival was $74.5 \%$, $67.1 \%$, and $39.6 \%$ respectively. Only operation type influenced event-free survival, with patients undergoing Mustard procedures having shorter event-free survival than those who had had Senning procedures initially (log-rank statistic $4.06, \mathrm{p}=0.044)$. This important difference persisted after adjusting for the potential confounding variable of the operation era (all the Senning operations were performed in the later surgical era, log rank statistic 3.99, $\mathrm{p}=0.046$; this is illustrated in fig 2).

\section{RHYTHM}

All patients were in sinus rhythm preoperatively. Detailed follow up of rhythm was examined in the hospital surviving cohort (22 Senning operation, 73 Mustard operation). "Interruption of sinus rhythm" was dated as the first nodal rhythm or supraventricular tachycardia, or significant pauses on routine or emergency ECG or 24 hour Holter monitoring, or history of cardiac syncope or sudden presumed cardiac death. "Serious arrhythmias" was dated from the first 


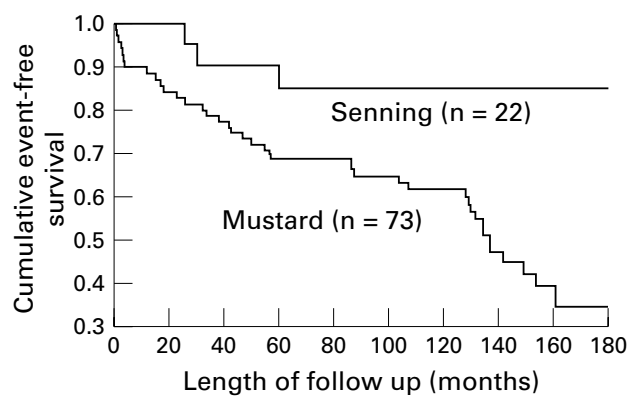

Figure 2 Event-free survival: comparison of Mustard and Senning cohorts (after adjustment for date of operation).

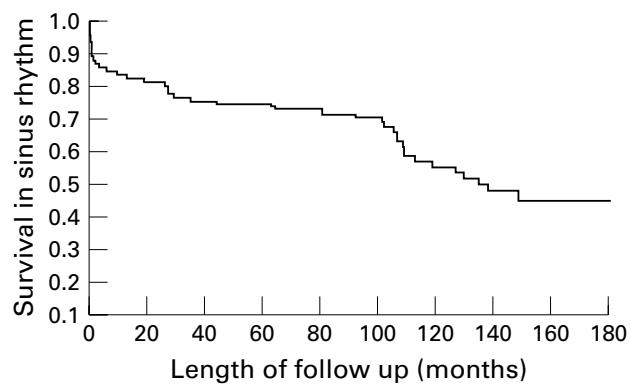

Figure 3 Kaplan-Meier curve of long term survival in sinus rhythm (hospital surviving cohort, $n=95$ ).

of supraventricular tachycardia or significant pauses or history of syncope or sudden presumed arrhythmic death.

Persistence of uninterrupted sinus rhythm at 5,10 , and 15 years occurred in $69.9 \%, 48.5 \%$, and $41.2 \%$ respectively. Figure 3 shows a Kaplan-Meier curve of survival in sinus rhythm. The only factor that influenced long term maintenance of sinus rhythm was operation type, with Mustard patients having a longer mean survival in sinus rhythm than Senning patients (93.5 $v 102.1$ months). However, only two of the 22 Senning patients had serious arrhythmias compared with 18 of the 73 Mustard patients $(p=0.059)$.

The influence of rhythm disturbance on late cardiac death in the cohort of hospital survivors was examined. Loss of sinus rhythm and occurrence of supraventricular tachycardia (predominantly atrial flutter), whether on routine ECG or Holter monitoring or on emergency ECG, were entered in a time dependent fashion in a Cox model. The relative risk of late cardiac death after losing sinus rhythm was 1.34 (95\% confidence interval 0.38 to 4.77 ) and was not significant. However, the occurrence of supraventricular tachycardia did increase the relative risk of late cardiac death by a factor of 8.72 (95\% confidence interval 2.86 to 26.64). Thirteen patients had a documented episode of supraventricular tachycardia and none of the eight variables predicted this.

REOPERATION

There were 22 reoperations in 20 patients $(21.1 \%)$. Thirteen of these were for baffle obstruction, six for baffle leaks, two for left ventricular outflow tract obstruction, and one for repair of coarctation. However, there were significantly more reoperations in the Mustard cohort $(19 / 73)$ than in the Senning cohort $(1 / 22)(\mathrm{p}=0.031)$.

\section{Discussion}

MORTALITY

There were 21 deaths before atrial inflow correction could be undertaken. This proportion is similar to previous studies. ${ }^{14-16}$ Fourteen operative deaths occurred within 30 days of atrial inflow correction from 109 operations, giving an operative mortality of $12.8 \%$. The late mortality rate was $12.8 \%$, with 5,10 , and 15 year survival of $77.3 \%, 75.9 \%$, and $71.3 \%$ respectively. The survival figures are similar to other large series. ${ }^{45}$

Two factors-greater than median age at operation (250 days) and later surgical erasignificantly influenced survival. We show that these factors had their influence during the immediate 30 day postoperative period. Two other studies have also shown that greater age at original operation has a positive influence on survival, ${ }^{46}$ although another has not. ${ }^{7}$ Two studies are in agreement with our other finding that patients in the later surgical era have better survival. $^{78}$

In our series, patients with complex lesions were less likely to survive than those with simple TGA but this did not reach statistical significance. Other studies have shown significantly reduced survival with complex TGA. ${ }^{9}{ }^{10}$

It has been suggested that Dacron baffles might lead to increased mortality by causing atrial flutter, ${ }^{6}$ but we found no evidence that the type of baffle material influenced early or late mortality. Similarly it has been suggested that poorer long term right ventricular function (leading to poorer survival) may be related to increased myocardial ischaemia at the time of the original operation ${ }^{8}$; however, we found no evidence to support this from an examination of the bypass and cross clamp times.

\section{CARDIAC EVENTS}

The 5, 10, and 15 year cardiac event-free survival figures (defined as death, reoperation, significant arrhythmia, pacemaker insertion, or clinical cardiac decompensation) were $74.5 \%$, $67.1 \%$, and $39.6 \%$ respectively for our group of initial hospital survivors. We show clear evidence for the first time that Senning patients have better event-free survival than Mustard patients (fig 2). Only one other report ${ }^{10}$ has performed a direct comparison of Mustard and Senning operations from the same centre. They found no differences between the groups with regard to baffle associated problems, right ventricular failure, or sudden death. Also only one other paper has analysed event-free survival as a composite end point: Myriodokis et al found an event-free survival at 15 years of $77 \%$ for the simple TGA group and $46 \%$ for the complex group. ${ }^{5}$ In our group, the complex patients also had poorer event-free survival but this did not reach statistical significance.

\section{RHYTHM}

The 5, 10, and 15 year figures for survival in sinus rhythm for the cohort of hospital survivors were $75.3 \%, 55.7 \%$, and $48.4 \%$. A similar steady loss of sinus rhythm has been shown in numerous other studies. ${ }^{561011}$ There was a trend for operation type to influence persistence 
of sinus rhythm, with Senning patients having a shorter mean survival in sinus rhythm (93.5 v 102.1 months). Two other studies have performed a similar comparison, with contradictory results. The first showed that more Mustard patients were in sinus rhythm after seven years of follow up (66 $v 56 \%)^{11}$; in contrast, the second study $^{10}$ showed that only $18 \%$ of Mustard patients were in sinus rhythm at 16 years of follow up compared with $53 \%$ of Senning patients $(p<0.001)$. In addition in our study 18 of 73 Mustard patients had a serious arrhythmia in comparison with two of 22 Senning patients $(p=0.059)$. Thus it seems that although Senning patients lose sinus rhythm more quickly, Mustard patients have more severe sinus node dysfunction.

Two papers have shown that the development of supraventricular arrhythmias, especially atrial flutter, is by far the most important risk factor for late death. Gewillig et al found that the occurrence of atrial flutter increased the risk of late death by a factor of 4.6 $(\mathrm{p}<0.0001),{ }^{6}$ while Helbing et al found that supraventricular tachycardia increased the risk of late death by $3.56 .{ }^{10}$ Our results are in agreement with these two studies, showing an increased instantaneous risk for late death of a factor of 8.72 (95\% confidence interval 2.86 to 26.64) after development of supraventricular tachycardia. None of the variables in table 2 influenced development of supraventricular tachycardia, although there was a trend to a higher incidence in Mustard patients (12 of 73) than in Senning patients (one of 22). We did not assess the relation between development of supraventricular tachycardia and haemodynamic status and in particular right ventricular function. However, previous investigators ${ }^{6}$ have shown that atrial flutter is preceded by right ventricular dysfunction in a significant proportion $(38 \%)$ and further tests revealed previously unsuspected venous pathway obstruction in another sizeable proportion. Thus the development of supraventricular tachycardia should provoke full investigation.

\section{REOPERATIONS}

Reoperations were performed in 20 patients $(21.0 \%)$. This is more than in other series $(4.4 \%$ to $13.3 \%){ }^{6-8}$ and reflects our longer period of follow up, the inclusion of complex TGA in our series, and also the unit policy of completely reinvestigating all our patients at around 12 years of age regardless of symptoms. Senning patients had significantly fewer reoperations than Mustard patients $(p=0.031)$ and this suggests that the Senning operations may lead to fewer baffle problems than the Mustard procedure, as has previously been postulated. ${ }^{7}$ However, it may also be relevant that all the Senning procedures were performed in the more recent surgical era while the Mustard operations were done in both eras.

CONCLUSIONS

We confirm the relatively good long term results from atrial inflow correction for TGA, with a 15 year survival of $71.3 \%$. However, there is an appreciable incidence of late cardiac death and events (with a 15 year event-free survival of $39.6 \%$ ).

The Senning procedure is preferable to the Mustard procedure for those cases unsuitable for arterial switching. We show clear evidence for the first time that Senning patients have better event-free survival. We have confirmed that the occurrence of supraventricular tachycardia is the only significant risk factor for late cardiac death (relative risk 8.72).

We are grateful to Mrs Jacky Clark and Mrs Rena Masson for secretarial help.

1 Tynan M, Anderson RH. Congenital heart disease. In: Julian DG, Camm AJ, Fox KM, Hall RJC, Poole-Wilson P, eds. Diseases of the heart. Philadelphia: WD Saunders, Diseases of the

2 Senning A. Surgical correction of transposition of the great vessels. Surgery 1959;45:966-80.

Mustard WT. Successful two-stage correction of transposition of the great vessels. Surgery 1964;55:469-72.

4 Darvell FJ, Rossi IR, Rossi MB, et al. Intermediate to late term results of Mustard's procedure for complete transposition of the great arteries with an intact ventricular septum. Br Heart $\mathcal{F}$ 1988;59:468-73.

5 Myriodokis DJ, Ehlers KH, Engle MA. Late follow up after venous switch operation (Mustard procedure) for simple and complex transposition of the great arteries. Am $\mathcal{f ~ C a r -}$ diol 1994;74:1030-6.

6 Gewillig M, Cullen S, Mertens B, et al. Risk factors for arrhythmia and death after Mustard operation for simple transposition of the great arteries. Circulation 1991; 84(suppl III):III-187-192.

7 Turina M, Siebenmann R, Nussbaumer P, et al. Long-term outlook after atrial correction of transposition of great outlook after atrial correction of transposition of

8 Trusler GA, William WG, Duncan KF, et al. Results with Trusler GA, William WG, Duncan KF, et al. Results with
the Mustard operation in simple transposition of the great arteries. Ann Surg 1987;206:251-60.

9 Ashraf MH, Cotroneo J, DiMarco D, et al. Fate of long-term survivors of Mustard procedure (inflow repair) for simple and complex transposition of the great arteries. Ann Thorac Surg 1986;42:385-9.

10 Helbing WA, Hansen B, Ottenkamp J, et al. Long-term results of atrial correction for transposition of the great arteries. Comparison of Mustard and Senning operations. $f$ Thorac Cardiovasc Surg 1994;108:363-72.

11 Deanfield J, Camm J, Macartney F, et al. Arrhythmia and late mortality after Mustard and Senning operation for transposition of the great arteries. An eight-year prospectransposition of the great arteries. An eight-year prosp
tive study. $\mathcal{F}$ Thorac Cardiovasc Surg 1988;96:569-76.

12 Flinn CJ, Wolff GS, Dick M, et al. Cardiac rhythm after the Mustard operation for complete transposition of the great arteries. N Engl F Med 1984;310:1635-9.

13 Norwood WJ, Dobell AR, Freed MD, et al. The Congenital Heart Surgeons Society. Intermediate results of the arterial switch repair. A 20 institution study. F Thorac Cardiovasc Surg 1988;96:854-63.

14 Mok Q, Darveu F, Matlos S, et al. Survival after balloon atrial septostomy for complete transposition of great arteries. Arch Dis Child 1987;62:549-53.

15 Paul MH. Transposition of the great arteries. In: Adams FH, Emmanailides GC, eds. Heart disease in infants, children and adolescents, 3rd ed. Baltimore: Williams and Wilkins, 1983.

16 Clarkson PM, Barratt Boyes BG, Neutze JM, et al. Results over a ten year period of palliation followed by corrective surgery for complete transposition of the great arteries. Circulation 1972;45:1251-8. 